\title{
Convergence of multiple markers and analysis methods defines the genetic distinctiveness of cryptic pitvipers
}

Mrinalini, M.; Thorpe, R.S.; Creer, S.; Lallias, D.S.; Dawnay, L.; Stuart, B.L.; Malhotra, A.

\section{Molecular Phylogenetics and Evolution}

DOI:

10.1016/j.ympev.2015.06.001

Published: 08/07/2015

Peer reviewed version

Cyswllt i'r cyhoeddiad / Link to publication

Dyfyniad o'r fersiwn a gyhoeddwyd / Citation for published version (APA):

Mrinalini, M., Thorpe, R. S., Creer, S., Lallias, D. S., Dawnay, L., Stuart, B. L., \& Malhotra, A. (2015). Convergence of multiple markers and analysis methods defines the genetic

distinctiveness of cryptic pitvipers. Molecular Phylogenetics and Evolution, 92, 266-279.

https://doi.org/10.1016/j.ympev.2015.06.001

\footnotetext{
Hawliau Cyffredinol / General rights

Copyright and moral rights for the publications made accessible in the public portal are retained by the authors and/or other copyright owners and it is a condition of accessing publications that users recognise and abide by the legal requirements associated with these rights.

- Users may download and print one copy of any publication from the public portal for the purpose of private study or research.

- You may not further distribute the material or use it for any profit-making activity or commercial gain

- You may freely distribute the URL identifying the publication in the public portal ?
}

Take down policy

If you believe that this document breaches copyright please contact us providing details, and we will remove access to the work immediately and investigate your claim. 
1 Convergence of multiple markers and analysis methods defines the genetic

2 distinctiveness of cryptic pitvipers

3

4 Mrinalini ${ }^{\mathrm{a},}{ }^{*}$, Roger S. Thorpe ${ }^{\mathrm{a}}$, Simon Creer $^{\mathrm{a}}$, Delphine Lallias ${ }^{\mathrm{a}}$, Louise Dawnay ${ }^{\mathrm{a}}$, Bryan L.

$5 \quad$ Stuart $^{\mathrm{b}}$, and Anita Malhotra ${ }^{\mathrm{a}}$

6

7 a School of Biological Sciences, College of Natural Sciences, Bangor University, Gwynedd,

$8 \quad$ LL57 2UW, UK.

$9 \quad{ }^{\mathrm{b}}$ North Carolina Museum of Natural Sciences, Raleigh, North Carolina, USA.

10

$11 *$ Corresponding Author

12 Mrinalini

13 Present Address: Department of Biological Sciences

14 National University of Singapore

15 Science Drive 4

$16 \quad$ Singapore 117543

17 Email: dbsmrin@nus.edu.sg

18

19 Abbreviated Title: Cryptic species delimitation using multiple markers and analysis methods.

20

21 


\section{Abstract}

Using multiple markers and multiple analytical approaches is critical for establishing species boundaries reliably, especially so in the case of cryptic species. Despite development of new and powerful analytical methods, most studies continue to adopt a few, with the choice often being subjective. One such example is routine analysis of Amplified Fragment Length Polymorphism (AFLP) data using population genetic models despite disparity between method assumptions and data properties. The application of newly developed methods for analyzing this dominant marker may not be entirely clear in the context of species delimitation. In this study, we use AFLPs and mtDNA to investigate cryptic speciation in the Trimeresurus macrops complex that belongs to a taxonomically difficult lineage of Asian pitvipers. We analyze AFLPs using population genetic, phylogenetic, multivariate statistical, and Bayes Factor Delimitation methods. A gene tree from three mtDNA markers provided additional evidence. Our results show that the inferences about species boundaries that can be derived from population genetic analysis of AFLPs have certain limitations. In contrast, four multivariate statistical analyses produced clear clusters that are consistent with each other, as well as with Bayes Factor Delimitation results, and with mtDNA and total evidence phylogenies. Furthermore, our results concur with allopatric distributions and patterns of variation in individual morphological characters previously identified in the three proposed species: T. macrops sensu stricto, T. cardamomensis, and T. rubeus. Our study provides evidence for reproductive isolation and genetic distinctiveness that define these taxa as full species. In addition, we re-emphasize the importance of examining congruence of results from multiple methods of AFLP analysis for inferring species diversity.

Keywords: AFLP; Dominant marker; Pitviper; Taxonomy; Population structure; 


\section{Introduction}

Current efforts to discover and delimit species are usually facilitated by DNA sequence-based evolutionary reconstructions. However, this can be biased by locus-specific evolutionary constraints and genomic non-representation. In the case of recently diverged species, short nuclear sequences are often phylogenetically uninformative (e.g. Bardeleben et al. 2005, Weisrock et al. 2010). Multilocus markers are therefore highly recommended and offer quantitative advantages and genome-wide coverage (Zhang and Hewitt 2003, Meyer and Paulay 2005, Brito and Edwards 2009, Dupuis et al. 2012, Leaché et al. 2014). Routine phylogenomic analysis is still constrained by issues such as differences in results across methods, the need to integrate evolutionary histories of multiple loci, the lack of guidelines for best practices, and extensive computational requirements (Song et al. 2012, Gatesy and Springer 2013, Dell'Ampio et al. 2014, Faria et al. 2014, Leaché et al. 2014). Nonetheless, new methods have been developed and high-throughput sequence analysis is gaining popularity in evolutionary and speciation research (Morin et al. 2010, Springer et al. 2012, McCormack 2013, Misof et al. 2014).

Alternatively, the use of non-sequence-based multilocus markers has also increased, often revealing surprisingly clear, fine-scale genetic structure undetected by morphology and sometimes even by mtDNA markers (Brown et al. 2007, Egger et al. 2007, Kingston et al. 2009, Meudt et al. 2009, Milá et al. 2010). Among these, Amplified Fragment Length Polymorphism (AFLP) (Vos et al. 1995) is a time-tested, cost-effective, and powerful technique requiring no sequence knowledge. AFLPs have continued to prove useful for resolving species-level taxonomy, recovering patterns of speciation, evolutionary histories and inter-relationships, inferring population structure and genetic diversity analyses in a wide-range of animal species, such as butterflies (Kronforst and Gilbert 2008, Quek et al. 
2010), cichlids (Albertson et al. 1999), salamanders (Wooten et al. 2010), lizards (Ogden and Thorpe 2002), dolphins (Kingston et al. 2009), and pinnipeds (Dasmahapatra et al. 2009).

\subsection{Dominant marker analysis}

Usually, multilocus markers are analyzed using genetic clustering and diversity analysis methods. These are implemented in population genetics models using F-statistics calculations based on allele-frequencies. The uses of these methods with respect to codominant datasets have been evaluated in both spatial and non-spatial models (Latch et al. 2006, Chen et al. 2007, Frantz et al. 2009). AFLPs, however, are dominant markers and do not allow distinction between homozygous and heterozygous states of an allele. Therefore, AFLP analysis using allele frequency-based population genetics models requires several assumptions to be made. As this results in analytical limitations, it is highly recommended that multiple analysis methods are applied, and inferences are made with high confidence only when results show congruence across methods (Carstens et al. 2013). However, the majority of AFLP studies continue to apply population genetic methods and derive biological inferences with rare discussion of possible analytical biases (Hollingsworth and Ennos 2004, Bonin et al. 2007). One such example is the routine use of the popular, non-spatial clustering program, STRUCTURE that uses a Bayesian MCMC algorithm to infer $\mathrm{K}$ - the number of populations. Other such programs include TESS, GENECLUST, and GENELAND that perform Bayesian cluster analysis under spatial models (Guillot et al. 2005a, 2005b, François et al. 2006, Chen et al. 2007, Guillot 2008, Guillot et al. 2008).

The algorithm used in STRUCTURE accommodates dominant data by assuming the presence of recessive alleles at a subset of loci that provide partial information about diploid genotypes for the entire dataset (Falush et al. 2007). GENELAND uses geographic coordinates and identifies groups of individuals in Hardy-Weinberg Equilibrium (HWE) 
97 (Guillot et al. 2005a, 2005b). GENELAND was upgraded to correct allele frequency estimates from dominant data by taking into account observed genotypes and estimating unknown genotypes using model-based MCMC simulations (Guillot and Santos 2010). However, both STRUCTURE and GENELAND still assume that AFLP null-alleles (i.e., band absences) are recessive alleles for allele frequency calculations and subsequent $\mathrm{K}$ estimation. Common assumptions that drive these analyses (such as HWE in a population and linkage disequilibrium between populations but not within populations) are conceptually not applicable to dominant data. The models and assumptions used for K estimation in STRUCTURE are less than straightforward and need to be used with caution as they could yield inaccurate results (Pritchard et al. 2000). Furthermore, the accuracy of K estimation using dominant datasets in GENELAND is lower than in co-dominant datasets (Guillot and Santos 2010). In some cases, tree-building analysis of AFLPs has performed better at cluster identification due to the absence of population genetics model assumptions (Meudt et al. 2009). A certain degree of uncertainty is therefore unavoidable when using population genetic models to estimate the number of $\mathrm{K}$, to assign individuals to each $\mathrm{K}$, and to assess the genetic structure of each K. Hence, the need for new and more appropriate methods for dominant marker analysis has been identified (Hollingsworth and Ennos 2004, Excoffier and Heckel 2006, Bonin et al. 2007, Meudt et al. 2009).

Multivariate methods (such as factor and cluster analysis, principal component analysis, Multi-Dimensional Scaling, Molecular Analysis of Variance) implemented outside the confines of population genetics models have been extensively used to analyze AFLPs. More recently, two tools that use a combination of multivariate procedures to analyze multilocus genetic data were developed. Discriminant Analysis of Principal Components (DAPC) was developed in adegenet (an R package) as a method for inferring genetic clusters and genetic diversity using dominant data (Jombart et al. 2010). Hausdorf and Hennig (2010) 
122 developed prabclus, also an R package, for species delimitation and ordination-cluster

123 analysis using both dominant and co-dominant datasets. Both adegenet and prabclus, have

124 performed better than STRUCTURE in initial studies (Hausdorf and Hennig 2010, Jombart et

125 al. 2010). These methods could be useful for cluster and population structure analyses and

126 speciation research that employ dominant markers.

127 Finally, Leaché et al. (2014) developed a new approach for AFLP and SNP based

128 species delimitation by adapting a method called Single Nucleotide Polymorphism and AFLP

129 Phylogenies (SNAPP) (Bryant et al. 2012). SNAPP produces posterior probability

130 distributions of allele frequency changes and allows species tree estimation without the need

131 for gene tree reconstruction and integration (Bryant et al. 2012). Grummer et al. (2013) first

132 developed sequence-based Bayes Factor Delimitation (BFD) to perform marginal likelihood

133 estimations (MLE) and test multiple species delimitation hypotheses. Species delimitation

134 models are tested at the same time as species tree estimation, forgoing the need to specify a

135 guide species tree (Grummer et al. 2013). Leaché et al. (2014) modified this and developed

136 SNAPP BFD for species delimitation using SNPs and AFLPs. SNAPP BFD is implemented

137 using MLE path sampling analysis in version 2 of Bayesian Evolutionary Analysis Sampling

138 Trees (BEAST) software (Drummond et al. 2012, Bouckaert et al. 2014).

139

$140 \quad$ 1.2 The study group - Trimeresurus (Trimeresurus) macrops

141 Asian green pitvipers from the genus Trimeresurus (Serpentes: Crotalidae: Crotalinae)

142 (Lacépède 1804) are well known for cryptic speciation (e.g. Malhotra and Thorpe 2000,

143 Vogel et al. 2004, Malhotra and Thorpe 2004a). The genus was divided into several genera in

1442004 (Malhotra and Thorpe 2004b), among which was Cryptelytrops (Cope 1860). Recently,

145 as a result of new information on the type species of Trimeresurus, Cryptelytrops was shown

146 to be a junior synonym of Trimeresurus (David et al. 2011). Therefore, the species placed in 
147 Cryptelytrops by Malhotra and Thorpe (2004b) are now correctly placed within Trimeresurus,

148 whether defined in a broader sense (by subsuming Malhotra and Thorpe's proposed genera as

149 subgenera) or narrower sense (continuing to accept the existence of several well-defined,

150 ecologically, genetically, and morphologically diagnosable generic-level units within the

151 former larger genus).

152 Trimeresurus macrops sensu lato (s.l.) is distributed across Thailand, Laos, Cambodia, 153 and Viet Nam, and was shown to consist of three cryptic species with disjunct geographic 154 ranges in the highlands of Cambodia (Fig. 1), distinguished by variations in several 155 individual morphological characters corresponding to their allopatric distributions (Malhotra 156 et al. 2011a). The populations have been proposed as three distinct species: (i) T. macrops 157 sensu stricto (s.s.) found in Thailand, south \& central Laos, and northeast Cambodia, (ii) $T$. cardamomensis (Cardamom Mountains green pitviper), from southeast Thailand and the

159 Cardamom mountains of southwest Cambodia, and (iii) T. rubeus (Ruby-eyed green pitviper), 160 found in southern Viet Nam and eastern Cambodia (Malhotra et al. 2011a). The morphology 161 and species ranges for each of these putative species have been fully described (Malhotra et 162 al. 2011a). A multivariate morphometric analysis, however, was not completely successful in separating the three species (Fig. A.1), possibly due to geographic variation within each of

164 the species. Thus, whether the three populations are genetically distinct lineages and are 165 reproductively isolated needs to be clarified to fully support their species status.

166 Here we use multiple genetic markers and analysis methodologies to investigate the 167 genetic distinctiveness of the three proposed species in the T. macrops complex. We use three mtDNA markers and multilocus nuclear marker set from AFLPs. We employ eight methods of AFLP analysis incorporating population genetic, phylogenetic, multivariate statistical, and Bayes Factor Delimitation approaches to confirm species boundaries. We provide a 
171 comprehensive description of methods and results, and discuss them within the framework of each method for a better understanding of AFLP analysis.

173

\section{Materials and methods}

\section{$175 \quad 2.1$ Sampling scheme}

All samples were obtained from field collections, museums and private collections.

177 Geographic distribution of samples within putative species ranges is as shown in Fig.1. Each

178 locality is represented by multiple specimens in most cases. A total of 39 samples were used

179 for mtDNA sequence analysis, including 22 samples of T. macrops s.s., 6 samples of $T$.

180 cardamomensis and 7 samples of T. rubeus. Samples covered the geographic distribution of

181 much of the known range of T. macrops $s$. l., and many of these also had morphological data

182 available. Two closely related species were also included: T. venustus ( 3 samples from South

183 Thailand and West Malaysia); and T. kanburiensis (1 sample, the only one available in our

184 collection).

185 For AFLP analysis, a total of 50 individuals were genotyped among which 34 were

186 shared with mtDNA analysis. Putative species in T. macrops s.l. were represented by: $T$.

187 macrops s.s. $=22$ samples (20 shared with mtDNA analysis); . cardamomensis $=6$ (all

188 shared with mtDNA analysis); and T. rubeus $=7$ (six shared with mtDNA analysis).

189 Additionally, 15 T. venustus were genotyped (three shared with mtDNA analysis). However,

190 the single T. kanburiensis sample available could not be successfully genotyped due to very

191 low DNA yield. Full sample details including museum voucher numbers are provided in

192 Table A.1

193

$194 \quad 2.2$ Experimental methods

$195 \quad$ 2.2.1 mtDNA amplification and sequencing 
Liver or muscle tissue in $80 \%$ ethanol, clippings of ventral scales in $80 \%$ ethanol, or

blood obtained from the caudal vein preserved in 5\% EDTA and SDS-Tris buffer $(100 \mathrm{mM}$

Tris, 3\% SDS) were used. Whole genomic DNA was extracted using standard salt

precipitation protocols (Sambrook et al. 1989). Three mitochondrial genes, 12S rRNA (12S), 16S rRNA (16S), and NADH4 (ND4), were amplified (as described in Malhotra et al. 2011b), cleaned with shrimp alkaline phosphatase and Exonuclease I (Werle et al. 1994), and sequenced using dye-labelled terminators (ABI PRISM ${ }^{\mathrm{TM}}$ BigDye $^{\mathrm{TM}}$ Terminator Cycle

\subsubsection{AFLP Genotyping}

Genomic DNA was extracted using GenElute ${ }^{\mathrm{TM}}$ Mammalian Genomic DNA Miniprep

Kit (Sigma-Aldrich). Extracts were duplicated for six samples using the same tissue type, and three samples using different tissue types, for repeatability tests, and negative controls (lacking any tissue) were included to monitor contamination. Extract quality was checked on 1\% Agarose-EtBr gels, DNA was quantified on a NanoDrop ND-1000 Spectrophotometer, and corrected to $10 \mathrm{ng}^{-1} \mathrm{l}^{-1}$ using $0.1 \mathrm{M}$ TE.

AFLPs were generated following the general protocol from Whitlock et al. (2008), but with specific modifications as follows. $100 \mathrm{ng}$ DNA was used per sample and $6.9 \mu \mathrm{l}$

214 digestion-ligation mix (final concentrations: $1 \mathrm{X}$ TA buffer, $0.17 \mu g \mu \mathrm{l}^{-1}$ bovine serum albumin,

$2150.059 \mathrm{U}_{\mu} \mathrm{l}^{-1}$ each of EcoRI and MseI enzymes, 0.3X T4 ligase buffer, $0.03 \mathrm{U}^{-1} \mathrm{l}^{-1} \mathrm{~T} 4 \mathrm{DNA}$

216 ligase, $0.74 \mu \mathrm{M}$ each of Eco and Mse adaptors with $3 \mu 1 \mathrm{~d}_{2} \mathrm{H}_{2} \mathrm{O}$ ) was added to make up a final 217 volume of $16.9 \mu \mathrm{l}$. This was incubated at $16^{\circ} \mathrm{C}$ for 16 hours in a preconditioned water bath in

218 ThermoFast ${ }^{\circledR}$ 96-well plates (ABgene) and diluted by a factor of 1:4 (i.e. to a final volume of 219 $50 \mu \mathrm{l}$ ) with $\mathrm{d}_{2} \mathrm{H}_{2} \mathrm{O}$. 
Pre-selective and selective primer sequences are provided in Table A.2. Fluorophore

221

222

223

224

225

226

227

228

229

230

231

232

233

234

235

236

237

238

239

240

241

242

243

244

labelling of selective primers at the 5 ' end was performed by Applied Biosystems ${ }^{\circledR}$ using

6FAM, VIC, and PET labels. Combinations of selective primers and fluorophore scheme are given in Table A.2. Pre-selective amplification (PA) reactions were performed using $1 \mu 1$ diluted ligated product in $10 \mu \mathrm{l}$ reactions (final concentrations: $1 \mathrm{X}$ PCR Buffer, $2 \mathrm{mM} \mathrm{MgCl}$, $0.2 \mathrm{mM}$ dNTP, $0.5 \mu \mathrm{M}$ each of pre-selective EcoRI and MseI primers, $0.025 \mathrm{U}_{\mu} \mathrm{l}^{-1}$

Thermoprime $\mathrm{Taq}$ ) with $4.15 \mu \mathrm{l} \mathrm{d}_{2} \mathrm{H}_{2} \mathrm{O}$. Thermocycling parameters were initial warm-up at $94^{\circ} \mathrm{C}$ for 2 minutes, 20 cycles of denaturing at $94^{\circ} \mathrm{C}$ for 30 seconds, annealing at $56^{\circ} \mathrm{C}$ for one minute, extension at $72^{\circ} \mathrm{C}$ for 2 minutes, and a final extension of $72^{\circ} \mathrm{C}$ for 10 minutes and $20^{\circ} \mathrm{C}$ for 5 minutes. PA products were diluted 1:10, and $1 \mu \mathrm{l}$ of each, along with $5 \mu 1$ loading buffer, was run on 1.5\% Agarose-EtBr gels. Successful PAs resulted in a smear across the whole range of a 500bp ladder. $1 \mu \mathrm{l}$ of diluted PA product was used for selective amplification (SA) in $10 \mu 1$ reactions with final concentrations same as PA except the primers were replaced by fluorophores and reverse selective primer. Thermocycling parameters were initial warm-up at $94^{\circ} \mathrm{C}$ for 2 minutes, 12 cycles of denaturing at $94^{\circ} \mathrm{C}$ for 30 seconds, annealing at $65^{\circ} \mathrm{C} \Delta-0.7^{\circ} \mathrm{C} /$ cycle for 30 seconds, extension at $72^{\circ} \mathrm{C}$ for 1 minute, 23 cycles of $94^{\circ} \mathrm{C}$ for 30 seconds, annealing at $56^{\circ} \mathrm{C}$ for 30 seconds, extension at $72^{\circ} \mathrm{C}$ for 1 minute, and a final extension of $72^{\circ} \mathrm{C}$ for 10 minutes and $20^{\circ} \mathrm{C}$ for 5 minutes. SA products were diluted at 1:100 and $1 \mu \mathrm{l}$ from each primer pair was poolplexed in $10 \mu \mathrm{l}$ formamide along with $0.5 \mu \mathrm{l}$ GeneScan $^{\mathrm{TM}} 500 \mathrm{LIZ}^{\circledR}$ Size Standard and the samples were processed on an ABI 3130XL Genetic Analyzer.

\subsection{AFLP peak scoring}

AFLP profiles were visualized and processed in GeneMapper ${ }^{\circledR}$ Software v4.0, and samples with amplification problems for one or more markers were discarded. Several 
automated and semi-automated AFLP scoring methods have been proposed in an effort to reduce time, error, and subjectivity of peak calling (reviewed in Meudt and Clarke (2007)).

247 We used the semi-automated method proposed by Whitlock et al. (2008) but found that direct application of this method to raw or filtered data (using the specified phenotype-calling threshold) resulted in significant numbers of inaccurate peak-calling from unaccounted false peaks (artefacts, inter-dye pull-ups, shoulder peaks, saturation peaks), peak mobility, and clear peaks failing to get called. Therefore, the data was first checked by eye and corrected for peak mobility, false peaks and uncalled peaks. Mean Peak Height (MPH) was calculated at each locus, a locus-selection threshold of 100 relative fluorescence units was applied. A relative phenotype-calling threshold of $20 \%$ of MPH was applied, i.e., all peaks $\geq 20 \% \mathrm{MPH}$ were marked as present (1) and peaks $\leq 20 \% \mathrm{MPH}$ were marked absent (0). We found our method, albeit time-consuming, significantly enhanced genotyping accuracy. Repeatability was measured as the number of loci with corresponding band presences across duplicated samples compared to the total number of loci scored.

\subsection{Data analysis}

\subsubsection{Bayesian phylogenetic analyses}

2.4.1.1 mtDNA phylogeny The mtDNA dataset consisted of $1450 \mathrm{bp}$ including $350 \mathrm{bp}$ of $12 \mathrm{~S}$, $474 \mathrm{bp}$ of $16 \mathrm{~S}$, and $626 \mathrm{bp}$ of ND4. The dataset was partitioned into $12 \mathrm{~S}, 16 \mathrm{~S}$, and first, second, and third codon positions for ND4. Models of sequence evolution were inferred in jModelTest 2.1 (Guindon and Gascuel 2003, Darriba et al. 2012) using the Akaike Information Criterion (Posada and Crandall 1998). Mixed-model Bayesian analysis was implemented in MrBayes 3.1 (Ronquist and Huelsenbeck 2003) using the following models: Generalized time-reversible with gamma-distributed rate variation $(\mathrm{GTR}+\mathrm{G})$ for $12 \mathrm{~S}$ and first and second codon positions of ND4; and GTR for 16S and third codon position of ND4. 
Viridovipera vogeli was used as outgroup. Four independent MCMC analyses of 15,000,000 cycles each (sampled every 3,000 generations) were performed with one cold chain and three heated chains. The first $25 \%$ of trees were discarded as burn-in and a 50\% majority-rule consensus tree was constructed from combined post-burn-in trees. Trace plots of clade probabilities were viewed using AWTY (Wilgenbusch et al. 2004).

\subsubsection{Total evidence and AFLP phylogenies Bayesian phylogenetic inference was} performed on both AFLP and total evidence (mtDNA + AFLP) datasets. A complex Bayesian model has been developed specifically for AFLP evolution (Luo et al. 2007). However the lack of algorithms and extreme computational burden (40,000 times slower than restriction site model implemented in MrBayes), make its implementation impractical (Koopman et al. 2008). We therefore used MrBayes 3.1 under the standard restriction data model by setting the coding bias to 'noabsencesites' for AFLP data to correct data for unobserved all-absence sites (Ronquist and Huelsenbeck 2003). The total evidence dataset was partitioned into AFLP, 12S, 16S, and ND4 partitions and model parameters estimated for mtDNA genes (Posada 2008). Four independent MCMC analyses were performed with 3 million cycles (sampled every 1000 generations) using one cold chain and three heated chains. The first 300,000 and 500,000 runs were discarded as burnin for AFLP and total evidence datasets respectively. A consensus tree was derived from post-burnin trees using all compatible groups. Final 50\% majority rule consensus trees were constructed and re-rooted using the basal clade from the mtDNA reconstruction in FigTree v1.1.2 (Rambaut and Drummond 2008).

\subsubsection{Bayes Factor Delimitation}

Bayes Factor species delimitation was performed using SNAPP BFD (Leaché et al. 2014) implemented in BEAST2 (Bouckaert et al. 2014). Five different speciation hypotheses 
were tested by lumping putative species in T. macrops s.l. in several combinations. In each hypothesis, T. venustus was included as a separate species. Details of speciation models are as follows with lumping of putative species indicated in parentheses: Model A: T. macrops s.s., T. cardamomensis, T. rubeus; Model B: (T. macrops s.s. + T. cardamomensis + T. rubeus); Model C: (T. macrops s.s.+ T. cardamomensis), T. rubeus; Model D: (T. macrops s.s. + T. rubeus), T. cardamomensis; Model E: T. macrops s.s., (T. cardamomensis + T. rubeus). Marginal likelihood estimation for each model was performed by path sampling conducted in 48 steps. MCMC chain length of 100,000 with pre-burnin of 10,000 for each step was sufficient to establish stationarity. The strength of support for competing models was evaluated as per Leaché et al. (2014), using the Kass and Raftery (1995) framework.

\subsubsection{Population genetics methods}

2.4.3.1 Descriptive statistics Estimating genetic diversity from dominant data under nonHWE is possible by incorporating population specific inbreeding co-efficients $\left(\mathrm{F}_{\text {is }}\right)$ into calculations of diversity indices such as $F_{\text {st }}$ (Yeh et al. 1997, Foll et al. 2008). Although $F_{\text {is }}$

310 values from small populations (less than 10 individuals) could be unreasonable (Holsinger and Lewis 2007), the difficulty of estimating allele frequencies from small populations could be overcome by analyzing a large number of loci (Krauss 2000). Given that sample sizes for two of our putative species were small (six and seven individuals), we incorporated $F_{\text {is }}$ values

314 from ABC4F (Foll et al. 2008) into $F_{\text {st }}$ calculations in POPGENE (Yeh et al. 1997) and also calculated $\mathrm{F}_{\text {st }}$ in the $f$ - free model in HICKORY 1.1 (Holsinger and Lewis 2007). An AMOVA was performed in GenAlex v6.3 (Peakall and Smouse 2006) to calculate \% genetic variance and $\Phi_{\mathrm{PT}}\left(\right.$ a distance-based analog of $\mathrm{F}_{\mathrm{st}}$ ) of populations, based on 9999 random permutations. 
2.4.3.2 Detection of outliers BayeScan v1.0 (Foll and Gaggiotti 2008) was used to test for outlier loci in AFLP data (Pérez-Figueroa et al. 2010). Model parameters were automatically estimated based on 10 pilot runs (length $=5,000$ ), using default chain parameters (sample size $=5,000$, thinning interval $=20$, and additional burn-in $=50,000)$. Jefferey's scale of evidence was set to maximum (decisive) and loci with $\log _{10}$ (Bayes Factor) $=2.0$ (corresponding to $p=0.99$ ) were considered outliers.

2.4.3.3 Estimation of historical gene flow Historical gene flow $\left(\mathrm{N}_{\mathrm{m}}\right)$ among populations was estimated indirectly by the average of effective number of migrants exchanged between populations in each generation. Crow and Aoki's correction was applied, i.e., $\mathrm{N}_{\mathrm{m}}=\left(1-\mathrm{F}_{\mathrm{st}}\right) / 4 \alpha$ $\mathrm{F}_{\mathrm{st}}$, where $\mathrm{N}_{\mathrm{m}}=$ the number of migrants per generation, and correction factor $\alpha=[\mathrm{n} /(\mathrm{n}-1)]^{2}$ where $\mathrm{n}=$ number of populations (Crow and Aoki 1984).

2.4.3.4 STRUCTURE Cluster analysis for dominant data was implemented in the admixture model using correlated allele frequencies - a more accurate model for assigning individuals to closely related groups (Pritchard et al. 2000, Falush et al. 2003, Falush et al. 2007). Ten runs of 100,000 iterations each were performed with $\mathrm{K}$ ranging from 1 to 10 , and burn-in of 10,000 iterations. Since estimating the probability of $K, \operatorname{Pr}(X \mid K)$, is computationally difficult, two ad hoc methods were used: $\operatorname{Ln} \operatorname{Pr}(\mathrm{X} \mid \mathrm{K})$, prescribed by Pritchard et al. (2000), and $\Delta \mathrm{K}$ based on the second order rate of change of likelihood function with respect to $\mathrm{K}$, proposed by Evanno et al. (2005). $\operatorname{Ln} \operatorname{Pr}(\mathrm{X} \mid \mathrm{K})$ and $\Delta \mathrm{K}$ for each $\mathrm{K}$ were plotted using STRUCTURE HARVESTER v0.56.4 (Earl and vonHoldt 2012). Assignment tests were performed to obtain the accuracy of assignment of individuals to putative species by including prior population membership information for each sample, and setting $\mathrm{K}=3$ and 4 based on $\Delta \mathrm{K}$ and $\mathrm{Ln}$ $\operatorname{Pr}(\mathrm{X} \mid \mathrm{K})$ plots. Q matrices of population membership from 10 replicates were permuted in the 
345 GREEDY_OPTION of CLUMPP v1.1.2 for a mean permuted matrix (Jakobsson and

346 Rosenberg 2007). Results were visualized in Distruct (Rosenberg 2004).

348 2.4.3.5 GENELAND Preliminary test runs of 200,000 iterations were used to check for

349 appropriateness of correlated and uncorrelated allele frequency model assumptions under

350 both spatial and non-spatial priors. Based on these results, four independent MCMC runs of

351500,000 iterations each were performed using a spatial prior with coordinate uncertainty

352 fixed at $1 \mathrm{~km}$, uncorrelated allele frequencies, minimum and maximum $\mathrm{K}$ fixed at 1 and 16 ,

353 and a burnin of 50,000 generations. An additional run of 1 million iterations and burnin of

354100,000 generations was also performed to check for differences in K estimation due to

355 increase in number of iterations. We tested the influence of spatial priors by rerunning the

356 analysis after swapping the geographic co-ordinates of sample B44 (whose cluster

357 assignment was incongruent with that of STRUCTURE) with that of sample A144 from north

358 Thailand.

359

$360 \quad$ 2.4.4 Multivariate statistical approaches

361 2.4.4.1 Principal co-ordinate analysis Principal co-ordinate analysis (PCoA), also known as

362 Classical Multidimensional Scaling, is a traditionally used cluster analysis that transforms

363 distances among objects into similarity/dissimilarity matrix (Gower 2005). This matrix is

364 used to position objects in a space of reduced dimensionality while retaining the relationships

365 between them. We performed a PCoA in MVSP v3.13n using Gower General Similarity Co-

366 efficient (Gower 1966, 1971) to derive the similarity index among pairs of taxa. The resulting

367 principal co-ordinates were plotted to visualize taxon clusters. 
2.4.4.2 Discriminant analysis of principal components Discriminant Analysis of Principal

370 Components (DAPC), implemented in adegenet in R, uses the find.clusters function to

371 perform a Principal Component Analysis (PCA) and estimate overall genetic variance. When

372 groups (such as species) are unknown, a K-means clustering algorithm divides total variance

373 into among-group and within-group components. We ran K-means clustering several times,

374 allowing $\mathrm{K}$ to vary from 1 to 49 in the first instance. Optimal number of clusters/putative

375 species was determined by the lowest Bayesian Information Criteria (BIC). Discriminant

376 Analysis (DA) of Principal Components (PCs) then defines a model which finds groups that

377 maximize among-group genetic variability and minimize within-group variability (Jombart et

378 al. 2010). We retained as many principal components in the preliminary data transformation

379 step as necessary to represent $75 \%$ of total genetic variation. The optimal number of PCs to

380 obtain a robust discrimination is estimated in optim.a.score, and the quality of discrimination

381 is indicated by a.score for each cluster. We performed 30 DAPC simulations in optim.a.score

382 for each of the 10 PCs retained. A second PCA, with K allowed to vary from 1 to 10 , was

383 performed to better visualize BIC results. A DAPC was performed using appropriate number

384 of PCs to maximize a.scores according to optim.a.score result.

2.4.4.3 Gaussian clustering In prabclus, a Non-Metric Multi-Dimensional Scaling (NMDS)

is performed on a distance matrix to derive Euclidean variables of genetic dissimilarity between individuals. Jaccard distances (Jaccard 1908) between individuals were calculated

389 from the binary matrix using the prabinit function. As with DAPC, BIC was used as an

390 indicator to estimate the number of clusters/putative species. A Gaussian mixture model

391 determined clusters of individuals corresponding to mixtures of normal distributions that

392 account for variation in data. Ten permutations of NMDS were performed on the distance

393 matrix by kruskal method in three dimensions using prabclust function. To visualize the 
394 clusters, the clusters object, showing assignment of individuals to each cluster, was exported to $R c m d r$ (Fox 2005).

396

2.4.4.4 Hierarchical clustering with seriation Finally, AFLP band presence and absence was visualized in PermutMatrix V1.9.3, a package originally developed for gene expression analysis (Caraux and Pinloche 2005). A Euclidean distance matrix of dissimilarity was generated and samples \& loci were clustered based on McQuitty's unsupervised hierarchical clustering with a multiple heuristic seriation rule. Row-wise (taxa) and column-wise (locus) enumeration was optimized to improve visualization.

403

404

\section{Results}

405

\subsection{Bayesian phylogenetic analyses}

3.1.1 mtDNA phylogeny Partitioned Bayesian mtDNA phylogeny showed T. macrops s.l. samples forming three distinct clades (Fig. 2a). Samples from Thailand, Laos, and northeast Cambodia were assigned to the nominate species T. macrops sensu stricto (T. macrops s.s.) since this clade included specimens from the type locality (Bangkok, Thailand). The second clade consists of samples from south-eastern provinces of Thailand and southwest Cambodia.

411 Finally, samples from southern Viet Nam and eastern Cambodia formed a sister group to all

412 above clades, and to T. kanburiensis. These relationships are strongly supported with

413 posterior probabilities of $100 \%$. Recognizing the second and the third clades as T. macrops

414 s.l. would render the species polyphyletic. The three clades therefore represent T. macrops s.s., T. cardamomensis, and T. rubeus respectively.

416

417 3.1.2 Total evidence phylogeny The total evidence phylogeny consisted of mtDNA

418 sequences and AFLP genotypes. The AFLP data comprised of 298 polymorphic loci from 
419330 loci with a repeatability score of $97 \%$ (for both duplicates for a given sample and for

420 different tissue types with different storage conditions for a given sample). The total evidence

421 tree (Fig. 2b) was topologically well-resolved and had robust support values. The three clades

422 in T. macrops s.l. were well-differentiated, with $100 \%$ support values at deeper nodes and

423 mostly high support values at the tips.

424

425

3.1.3 AFLP phylogeny The Bayesian AFLP tree (Fig. A.2) was poorly resolved at deeper nodes, with low support values. T. cardamomensis and T. venustus were not distinct from specimens of T. macrops s.s.

\subsection{Bayes Factor Delimitation}

For each speciation hypothesis, marginal likelihood values from SNAPP BFD analysis are shown in Table 2. All models derived by lumping of the three putative species in T. macrops s.l. in various combinations were decisively rejected based on $2 \times \log _{\mathrm{e}} \mathrm{BF}>10$. Model A consisting of four species, where T. macrops s.s., T. cardamomensis, and T. rubeus were hypothesized to be three distinct species, was the most favored model.

\subsection{Population genetics methods of AFLP analysis}

\subsubsection{Genetic differentiation and historical gene flow}

$\mathrm{F}_{\mathrm{st}}$ was 0.5 on average in both POPGENE and HICKORY. The $\%$ variation within and among putative species from AMOVA was $46 \%$ and $54 \%$ respectively. Overall $\Phi_{\mathrm{PT}}$ was 0.538 and $\Phi_{\mathrm{PT}}$ between populations are given in Table 1 . The $\%$ polymorphic loci for T. macrops

443 Estimated historical gene flow, $\mathrm{N}_{\mathrm{m}}$, among populations was 0.14. 


\subsubsection{Non-spatial and spatial Bayesian MCMC cluster analysis}

In STRUCTURE, $\operatorname{Ln} \operatorname{Pr}(X \mid K)$ increased by large increments up to $K=4$, while the increase was small at $K=5$ and decreased after $K=6$ (Fig. A.4a). With Evanno's methods, $\Delta K$ clearly peaked at three populations (Fig. A.4b). A graph estimating population structure for $\mathrm{K}=4$ (including $T$. venustus) is given in Fig. 3. The probability of each individual belonging to assigned species is given in Table A.3. The probabilities of individual assignments when $K=3$ (Evanno's method) were nearly all equal to 1.0.

In GENELAND, three clusters could be visualized from the posterior distribution.

Maps of individual posterior probabilities of membership to each cluster are given in Fig. 4.

All individuals from the T. cardamomensis cluster were assigned to T. macrops s.s. Posterior probabilities of cluster membership for individual samples are given in Table A.4. The sample switching experiment showed that probability of membership of sample B44 to T. macrops s.s. increased to $p=0.693$ and to $T$. venustus decreased to $p=0.158$. Probability of membership of sample A144 to T. macrops s.s. decreased to $p=0.550$ (from $p=0.664$ ) and to T. venustus increased to $p=0.304$ (from $p=0.158$ ).

460

\subsection{Multivariate statistical analysis of AFLPs}

PCoA showed that $\sim 50 \%$ of total variation was explained by the first three axes.

These accounted for $24 \%, 18 \%$ and $7 \%$ of observed variation. A scatterplot showed the three proposed species formerly within T. macrops to be well separated on axes 1 and 3 (Fig. 5a). 
469 distributions and mtDNA clades. The a.score for each cluster was: $T$. macrops s.s. $=0.15, T$.

470 cardamomensis $=0.96$, T. rubeus $=0.97$, and $T$. venustus $=0.68$.

In prabclus four species clusters (including T. venustus) were detected and clearly

separated in dimensions 1 and 3 with $100 \%$ accuracy of individual assignment to respective clusters (Fig. 5c). No datapoints were classified as noise components in this analysis (Fraley and Raftery 1998, 2002, Hausdorf and Hennig 2010).

Euclidean distance based hierarchical clustering and seriation also showed three results are presented in the graphical abstract, and full results are provided in Fig. A.6. T. macrops s.s. and T. cardamomensis samples differentiated into two distinct clusters within a single large cluster, except for ambiguous placement of A144. The position of T. venustus, nested within T. macrops s.l., was congruent with phylogenetic analyses.

\section{Discussion}

\subsection{Overview}

In the majority of cryptic speciation studies, morphological conservativeness, parallel and convergent evolution of phenotypic traits, and/or mimicry (Sanders et al. 2006), driven by natural selection, sexual selection, and ecological adaptation, confound species delimitation. Southeast Asian green or "bamboo" pitvipers are typical in this sense due to their general morphological conservativeness or environmentally driven morphological convergence (Sanders et al. 2004). This is further complicated by sampling difficulties, due to

490 cryptic life-styles of snakes, which can be a major drawback in population genetics analyses.

491 In such cases, multiple markers and analysis methods may provide critical information to 492 derive robust inferences on species diversity (Dupuis et al. 2012, Carstens 2013).

493 Traditionally used in population genetics, AFLPs have recently found application in species 
494 delimitation of a variety of plants (e.g. Prebble et al. 2012, Medrano et al. 2014) and animals

495 (e.g. Nie et al. 2012, Arthofer et al. 2013). Surprisingly, very few studies compare results

496 from multiple analysis methods (eg: Meudt et al. 2009, Reeves and Richards 2011). Most

497 comparative studies have only assessed genetic similarity co-efficients and multivariate

498 clustering methods such as UPGMA and NJ (Meyer et al. 2004, Kosman and Leonard 2005,

499 Dalirsefat et al. 2009).

500 In our investigation of cryptic speciation in T. macrops, we used three mtDNA

501 markers and 298 polymorphic AFLP loci and eight analysis methods. Of these, results from

502 two Bayesian phylogenetic analyses (total evidence and mtDNA), Bayes Factor Delimitation,

503 four multivariate statistical methods of AFLPs (PCoA, DAPC, Gaussian clustering, and

504 hierarchical clustering), and to a certain degree one population genetic method

505 (STRUCTURE) were congruent with each other. Moreover, these genetic results correspond

506 to allopatric geographic ranges and individual morphological characters described for each

507 species (Malhotra et al. 2011a). This gives us high confidence in the genetic distinctiveness of

508 T. macrops s.s., T. cardamomensis, and T. rubeus (Malhotra et al. 2011a).

509 In contrast, GENELAND was the only method that gave a contradictory result. This

510 brings into question the appropriateness of using GENELAND for a system such as this, and

511 we discuss this further in subsequent sections. The AFLP-only phylogenetic analysis, with

512 low support values, was unreliable. It is likely that low confidence can be placed in these two

513 results. We discuss our results and evaluate inferences in the context of dominant marker

514 analysis methods and provide a comparative assessment of phylogenetic, Bayes Factor

515 Delimitation, spatial and non-spatial Bayesian clustering methods, DAPC, Gaussian

516 clustering, and finally hierarchical clustering.

$518 \quad 4.2$ Comparative assessment of results from AFLP analysis 


\subsubsection{Phylogenetic analyses}

The resolution in total evidence Bayesian phylogenetic reconstruction matched that of traditionally used mtDNA markers, producing a robust phylogeny with three distinct clades in T. macrops (Fig. 2a \& b). The AFLP tree, however, showed poor resolution of species and low support values at deeper nodes (Fig. A.2). This difference in result indicates a stronger phylogenetic signal from the mtDNA sequence data. AFLP-based phylogenetic analyses have been largely confined to distance-based methods such as Neighbor-Joining and UPGMA in the past. However, despite homology and non-independence of fragments, AFLP phylogenies can successfully delimit species, sometimes performing better than STRUCTURE (Meudt et al. 2009) and even mtDNA markers (Mendelson and Simons 2006, Kingston et al. 2009).

Combined AFLP and mtDNA datasets can yield robust phylogenies and provide evidence for interspecific hybridization (Després et al. 2003, Pelser et al. 2003, Koopman 2005, Meudt and Clarke 2007, Kingston et al. 2009). There have been conflicting reports on the utility of AFLPs at deeper phylogenetic or interspecific levels as it appears to be affected by a drastic increase in non-homologous shared fragments resulting in loss of phylogenetic signal (Althoff et al. 2007, Dasmahapatra et al. 2009, Graves 2009, Kingston et al. 2009, GarcíaPereira et al. 2014). Moreover, choice of bands and tree-building methods, and application of restriction sites models, could over-simplify complex evolutionary processes, thus affecting resolution of deeper nodes (Dasmahapatra et al. 2009, Graves 2009). Finally, the more complex model developed specifically for AFLPs (Luo et al. 2007) has been found to be extremely computationally burdensome, making it impractical to implement (Koopman et al. 2008, Dasmahapatra et al. 2009). The failure of our AFLP reconstruction under a restriction site model reinforces the need for better, practical, and exclusive phylogenetic methods (Graves 2009). 


\subsubsection{Bayes Factor Delimitation}

SNAPP-BFD offers the advantage of testing multiple species hypothesis by

integrating topologies during marginal likelihood estimation and thereby avoiding the need to predefine the species tree and biasing support (Leaché et al. 2014). From our SNAPP-BFD analysis, Bayes Factors ranked the four species model (three from T. macrops complex and $T$. venustus) as the most highly favored model (Marginal Likelihood=-3757) (Table 2). Model E, where we lumped T. macrops s.s., T. cardamomensis and T. rubeus into a single species, received the lowest support (Marginal Likelihood $=-4587 ; 2 \mathrm{x} \log _{\mathrm{e}}$ Bayes Factor $\left.=1660\right)$ and was ranked last among the five models tested. Therefore, the hypotheses that consider $T$. macrops s.l. as a single species, or as consisting of two species, are not supported by SNAPPBFD analysis.

\subsubsection{Non-spatial and spatial Bayesian MCMC clustering analyses}

Both STRUCTURE and GENELAND use Bayesian MCMC methods to assign individuals probabilistically to populations based on allele frequencies. They cluster groups of individuals into populations by assuming that they are in HWE and linkage equilibrium. In the estimation of number of clusters (K), both STRUCTURE and GENELAND failed to differentiate $T$. cardamomensis as a separate species cluster and returned $\mathrm{K}=3$ by grouping these specimens in a single cluster with T. macrops s.s. (Fig. $3 \& 4$ ).

In STRUCTURE, the Pritchard et. al. (2000) method was inconclusive as to whether K equalled 3, 4, or even 5, as results depended on what cut off was applied to the $\operatorname{Ln} \operatorname{Pr}(\mathrm{X} \mid \mathrm{K})$ increase (Fig A.4a). In contrast, Evanno's method gave us a clear result of $\mathrm{K}=3$ (Fig. A.4b). Applying Evanno's correction is the norm for $\mathrm{K}$ estimation, since it is more formal and is endorsed by Pritchard et al. (2007). However, the Pritchard et. al. (2000) method of K estimation, which is said to be unreliable, subjective, and sometimes biologically 
569

570

571

572

573

574

575

576

577

578

579

580

581

582

583

584

585

586

587

588

589

590

591

592

meaningless, proved more realistic when the $\operatorname{Ln} \operatorname{Pr}(\mathrm{X} \mid \mathrm{K})$ values were compared. The $\mathrm{Ln}$ $\operatorname{Pr}(\mathrm{X} \mid \mathrm{K})$ increase from $\mathrm{K}=3$ to 4 was $8.57 \%$, approximately $50 \%$ of increase from both $\mathrm{K}=1$ to 2 and $\mathrm{K}=2$ to 3 , whereas it dropped to $2.1 \%$ for $\mathrm{K}=4$ to 5 (Table A.5). Moreover, there are several cases of $\mathrm{K}$ underestimation, and STRUCTURE results are said to be conservative when Evanno's method is applied (e.g., Frantz et al. 2009, Blanquer and Uriz 2010).

Therefore, based on our phylogenetic results and taking into consideration that $K=4$ proved a better estimation in the Pritchard et al. (2000) method of K estimation, we calculated the individual assignment probabilities by assigning individuals in T. macrops s.l. to three clusters and $T$. venustus individuals to a fourth cluster. The mean permuted assignment probability value ( $p$ ) for T. cardamomensis individuals to a separate cluster (as per CLUMPP) was only slightly lower at $p=0.969$ compared to T. macrops s.s $(p=1.0)$, T. rubeus $(p=$ 0.999), and T. venustus ( $p=0.999$ ). This further increased our confidence that Evanno's method underestimated $\mathrm{K}$ by grouping T. cardamomensis with T. macrops s.s.

In GENELAND, however, all individuals of T. cardamomensis as well as T. macrops s.s. were assigned to T. macrops s.s. with a probability of assignment $p=0.644$. Among the T. macrops s.s. samples, specimen B44, reportedly from Nakhon Si Thammarat in southern Thailand, was an exception with a lower probability of assignment to T. macrops s.s ( $p=$ 0.441). Moreover, while the probability of assignment of all other T. macrops s.s. specimens to $T$. venustus was $p=0.158$, that of sample B44 was higher at $p=0.363$. In contrast, the STRUCTURE analysis assigned B44 to T. macrops s.s. with a maximum mean permuted probability of 1.0 by CLUMPP. This specimen was the only T. macrops s.s. specimen reported from southern Thailand and as it was obtained from a dealer, the presence of this species at the reported locality is unconfirmed. Our suspicion, that this difference in assignment between GENELAND and STRUCTURE was due to the influence of spatial 
593 priors on individual assignment probabilities in GENELAND, was supported by a sample 594 switching analysis.

595 The apparent interruption of gene flow represented by the Gulf of Thailand, which 596 currently separates populations in the south of Thailand from populations in Cambodia and

597 Vietnam, might be considered to invalidate the GENELAND results. However, it is important 598 to consider the context at the time these species were evolving. The Gulf of Thailand has a maximum depth of $80 \mathrm{~m}$, and Voris (2000) showed that for c. $35 \%$ of the last 170,000 years, it would have largely been dry land. While this precision is only possible for relatively recent timescales, it is also known that there have been sea level fluctuations of similar magnitudes during the last 30 my (Hall and Holloway, 1998).

Allele-frequency estimations from small populations could be compensated by analyzing large number of loci (Krauss 2000). Our AFLP dataset was large (298 loci), yet the genetic diversity indices show a clear bias caused by small sample sizes of $T$. cardamomensis and $T$. rubeus, since the $\%$ polymorphic loci decreased considerably relative to population

607 size. $F_{\text {st }}$ values were much lower for T. cardamomensis and T. rubeus $(0.0507$ and 0.00729 , $608 p<0.00001)$ as opposed to T. macrops s.s. and T. venustus $(0.9, p<0.00001)$. However, $\Phi_{\mathrm{PT}}$ 609 values showed T. cardamomensis to be less genetically distinct from T. macrops s.s. than $T$. 610 rubeus (Table 1). These estimates appear to be non-representative, with biases arising from 611 sampling deficiency, probably insufficient number of loci, as well as dominant nature of the 612 marker. Hence deriving any strong biological inferences from diversity indices would be 613 highly dubious. Our estimation of historical gene flow among T. macrops complex 614 populations was low $\left(\mathrm{N}_{\mathrm{m}}=0.14\right)$, although $\mathrm{N}_{\mathrm{m}}$ calculation is based on $\mathrm{F}_{\text {st. }}$. Moreover, 615 considering the wider geographic distribution of T. macrops complex and geographical 616 barriers in southeast Asia, it is likely that there is established allopatry among populations. 617 Therefore, it seems highly likely that implementing GENELAND (which is more appropriate 
618 for systems with contemporary gene flow) may not have been ideal for the T. macrops

619 complex. It is difficult to predict whether increasing sample size may have provided better

620 resolution for T. cardamomensis in STRUCTURE and GENELAND. Trimeresurus rubeus

621 (represented by only seven individuals), was still sufficiently genetically diversified to form a

622 separate cluster as well as achieve $100 \%$ individual assignment success in all analysis

623 methods.

624

625

4.2.4 Multivariate statistical methods

626

Multivariate techniques proved superior to Bayesian MCMC clustering in terms of

627 sensitivity and confidence as PCoA, DAPC, Gaussian clustering, and hierarchical clustering

628 all split $T$. macrops s.l. into three clusters and also assigned individuals to their corresponding mtDNA clades with $100 \%$ success (Fig. 5a, b, \& c and Fig. A.6).

630

In DAPC analysis, optim.a.score recognized that the first three PCs would give

631 highest a.scores. Although they represented only $45 \%$ of total variance, we used the first

632 three PCs to obtain a strong and stable DAPC solution (Thibaut Jombart, personal

633 communication). a.scores were very high for T. cardamomensis and T. rubeus (0.96 and

634 0.97), and this increases our confidence that these two groups are genetically distinct. $T$.

635 macrops s.s. had an a. score of 0.15 , but given that some issues still exist with optim.a.score

636 and a.score functions (e.g., with repeatability), a more critical review of these scores is not

637 justified at this stage. Gaussian clustering in prabclus was highly successful, defining three

638 clusters of T. macrops and assigning individuals accurately to them. It is important to note

639 that both DAPC and Gaussian clustering were not affected by any sampling deficiency or by

640 lower level of genetic diversity of $T$. cardamomensis, which was always identified as a

641 separate cluster, in contrast to Bayesian clustering. 
642 Finally, the Euclidean distance-based hierarchical clustering and seriation also showed

643 distinct clustering of four species with T. venustus nested in T. macrops s.l.. T. macrops s.s.

644 and T. cardamomensis each formed a distinct sub-cluster within a single large cluster (Fig.

645 A.6). Locus-based (column-wise) clustering identified regions of banding dissimilarity across

646 the three species in T. macrops s.l. (Graphical Abstract). Sample A144, which clustered with

647 T. cardamomensis is the only representative from North Thailand (Jae Sorn NP, Lampang

648 province) and likely a genetic outlier. It is interesting that this was only apparent in the

649 hierarchical clustering analysis.

650

6515 Conclusions

652 Our study provides the genetic evidence required to complete investigations into the

653 morphologically cryptic species in the Trimeresurus macrops complex. Congruence of results

654 between multiple markers and methodologies clearly demarcates the three proposed species

655 as genetically and reproductively isolated. We therefore confirm Trimeresurus macrops s.s.,

656 T. cardamomensis, and T. rubeus as full species. Further, our study reinforces the importance

657 of using appropriate and multiple analysis methods and performing a comparative assessment

658 before deriving inferences on species diversity. The study also demonstrates the continued

659 utility of AFLPs for cryptic species delimitation and discovery, when high cost and

660 sequencing noise can be deterrents for using high-throughput sequencing (e.g. RAD-Seq)

661 (Davey et al. 2013).

662 


\section{ACKNOWLEDGEMENTS}

664 AM and RST are grateful to the large numbers of people who have assisted in the field,

665 including T. Chan-ard, J. Nabhitabhata (National Science Museum of Thailand), L.

666 Chanhome (Queen Savoabha Memorial Institute, Thailand), K. Thirakhupt and P-P. van Dijk

667 (Chulalongkorn University, Thailand), C. Rangsiyanon (Chiang Mai University), S. Paglia,

668 M. Cox, J. Murray, and T-X. Kiem (Cho-Ray Hospital, Viet Nam). We gratefully

669 acknowledge the National Science Council of Thailand and the Ministry of Health, Viet Nam

670 for permission to carry out fieldwork. This study was funded (AM/RST) by the Leverhulme

671 Trust (F174/I), the Wellcome Trust (057257/Z/99/Z and 060384/Z/00/Z), the Darwin

672 Initiative (162/6/65), a Sir Kenneth Blaxter Scholarship (British Society of Animal Science,

673 2007) to Mrinalini, the Royal Society, the Percy Sladen Trust, the Bonhote Trust, and the

674 Carnegie Trust. We also thank K. Udomritthiruj and G. Vogel for donation of specimens. The

675 opportunity for BLS to work in Laos was made possible by the Wildlife Conservation Society

676 / Division of Forest Resource Conservation Cooperative Program, and in Cambodia by the

677 Wildlife Conservation Society / Ministry of Agriculture, Forestry and Fisheries / Ministry of

678 Environment Cooperative Program. The Ministry of Agriculture and Forestry (Vientiane,

679 Laos) and Ministry of Agriculture, Forestry and Fisheries (Phnom Penh, Cambodia)

680 permitted export of specimens to the Field Museum. BLS was supported by the John D. and

681 Catherine T. MacArthur Foundation, the National Geographic Society (grant No. 6247-98),

682 the Wildlife Conservation Society, and the U.S. National Science Foundation (DEB-

683 1145922). H. Heatwole, David Emmett, T. Neang, S. Platt, K. Sok, and B. Thaovanseng are

684 thanked for fieldwork assistance, and M. Hedemark, A. Johnson, T. Hansel, J. Walston, and

685 C. Poole are thanked for logistical support.

686

687 
688

689

690

691

692

693

694

695

696

697

698

699

700

701

702

703

704

705

706

707

708

709

710

711 Bouckaert, R., Heled, J., Kühnert, D., Vaughan, T., Wu, C-H., Xie, D., Suchard, MA.,

712 Rambaut, A., \& Drummond, A. J. 2014. BEAST 2: A Software Platform for Bayesian

\section{References}

Albertson, R.C., Markert, J.A., Danley, P.D., Kocher, T.D. 1999. Phylogeny of a rapidly evolving clade: The cichlid fishes of Lake Malawi, East Africa. Proc. Natl. Acad. Sci. U.S.A. 96:5107-5110.

Althoff, D.M., Gitzendanner, M.A., Segraves, K.A. 2007. The utility of amplified fragment length polymorphisms in phylogenetics: a comparison of homology within and between genomes. Syst. Biol. 56:477-484.

Arthofer, W., Rauch, H., Thaler-Knoflach, B., Moder, K., Muster, C., Schlick-Steiner, B.C., Steiner, F.M. 2013. How diverse is Mitopus morio? Integrative taxonomy detects cryptic species in a small-scale sample of a widespread harvestman. Mol. Ecol. 22:3850-3863.

Bardeleben, C., Moore, R.L., Wayne, R.K. 2005. A molecular phylogeny of the Canidae based on six nuclear loci. Mol. Phylogenet. Evol. 37:815-831.

Blanquer, A., Uriz, M.J. 2010. Population genetics at three spatial scales of a rare sponge living in fragmented habitats. BMC Evol. Biol. 10:13.

Bonin, A., Ehrich, D., Manel, S. 2007. Statistical analysis of amplified fragment length polymorphism data: a toolbox for molecular ecologists and evolutionists. Mol. Ecol. $16: 3737-3758$. 
713 Evolutionary Analysis. PLoS Comp. Biol. 10(4): e1003537. doi:

714 10.1371/journal.pcbi.1003537.

715

716 Brito, P.H., Edwards, S.V. 2009. Multilocus phylogeography and phylogenetics using

717 sequence-based markers. Genetica 135:439-455.

718

719 Brown, D.M., Brenneman, R.A., Koepfli, K-P., Pollinger, J.P., Milá, B., Georgiadis, N.J.,

720 Louis Jr, E.E., Grether, G.F., Jacobs, D.K., Wayne, R.K. 2007. Extensive population genetic

721 structure in the giraffe. BMC Biol. 5:57.

722

723 Bryant, D., Bouckaert, R., Felsenstein, J., Rosenberg, N. A., and RoyChoudhury, A. 2012.

724 Inferring species trees directly from biallelic genetic markers: bypassing gene trees in a full

725 coalescent analysis. Mol. Biol. Evol. 29:1917-1932.

726

727 Caraux G., Pinloche S. 2005. A software for analysing and visualising data. Bioinformatics. $728 \quad 21: 1280-1281$.

729

730 Carstens, B.C., Pelletier, T.A., Reid, N.M., Satler, J.D. 2013. How to fail at species

731 delimitation. Mol. Ecol. 22:4369-4383.

732

733 Chen, C., Durand, E., Forbes, F., François, O. 2007. Bayesian clustering algorithms

734 ascertaining spatial population structure: a new computer program and a comparison study.

735 Mol. Ecol. Notes. 7:747-756.

736

737 Cope, E.D. 1860. Catalogue of the venomous serpents in the museum of the Academy of 
738 Natural Sciences of Philadelphia, with notes on the families, genera, and species. Proc. Acad.

739 Natl. Sci. Phil. 11:332-347.

740

741 Crow, J.F., Aoki, K. 1984. Group selection for a polygenic behavioral trait: estimating the

742 degree of populations subdivision. Proc. Natl. Acad. Sci. U.S.A. 81:6073-6077.

743

744 Dalirsefat, S., Meyer, A., Mirhoseini, S. 2009. Comparison of similarity coefficients used for 745 cluster analysis with amplified fragment length polymorphism markers in the silkworm,

746 Bombyx mori. J. Insect Sci. 9:71.

747

748 Darriba, D., Taboada, G.L., Doallo, R., Posada, D. 2012. jModelTest 2: more models, new 749 heuristics and parallel computing. Nature Methods 9(8):772.

750

751 Dasmahapatra, K.K., Hoffman, J.I., Amos, W. 2009. Pinniped phylogenetic relationships 752 inferred using AFLP markers. Heredity 103:168-177.

753

754 Davey, J.W., Cezard, T., Fuentes-Urtilla, P., Eland, C., Gharbi, K., Blaxter, M.L. 2013.

755

Special features of RAD Sequencing data: implications for genotyping. Mol. Ecol. 22:3151-

756 3164.

757

758 David, P., Vogel, G., Dubois, A. 2011. On the need to follow rigorously the Rules of the

759 Code for the subsequent designation of a nucleospecies (type species) for a nominal genus

760 which lacked one: the case of the nominal genus Trimeresurus, Lacépède, 1804 (Reptilia:

761 Squamata: Viperidae). Zootaxa 2992:1-51. 
763

764

765

766

767

768

769

770

771

772

773

774

775

776

777

778

779

780

781

782

783

784

785

786

787

Dell’Ampio, E., Meusemann, K., Szucsich, N.U., Peters, R.S., Meyer, B., Borner, J., Petersen, M., Aberer, A.J., Stamatakis, A., Walzl, M.G., Minh, B.Q., von Haeseler, A., Ebersberger, I., Pass, G., Misof, B. 2014. Decisive data sets in phylogenomics: Lessons from studies on the phylogenetic relationships of primarily wingless insects. Mol. Biol. Evol. 31:239-249.

Després, L., Gielly, L., Redoutet, B., Tabarlet, P. 2003. Using AFLP to resolve phylogenetic relationships in a morphologically diversified plant species complex when nuclear and chloroplast sequences fail to reveal variability. Mol. Phylogenet. Evol. 27:185-196.

Drummond, A.J., Suchard, M.A., Xie, D., Rambaut, A. 2012. Bayesian phylogenetics with BEAUti and the BEAST 1.7 Mol. Biol. Evol. 29: 1969-1973.

Dupuis, J.R., Roe, A.D., Sperling, F.A. 2012. Multi-locus species delimitation in closely related animals and fungi: one marker is not enough. Mol. Ecol. 21:4422-36.

Earl, D.A., vonHoldt, B.M. 2012. STRUCTURE HARVESTER: a website and program for visualizing STRUCTURE output and implementing the Evanno method. Conserv. Genet. Resour. 4:359-361.

Egger, B., Koblmüller, S., Sturmbauer, C., Sefc, K.M. 2007. Nuclear and mitochondrial data reveal different evolutionary processes in the Lake Tanganyika cichlid genus Tropheus. BMC Evol. Biol. 7:137.

\section{Evanno, G., Regnaut, S., Goudet, J. 2005. Detecting the number of clusters of individuals} using the software STRUCTURE: a simulation study. Mol. Ecol. 14:2611-2620. 
789 Excoffier, L., Heckel, G. 2006. Computer programs for population genetics data analysis: a 790 survival guide. Nat. Rev. Genet. 7:745-758.

791

792 Falush, D., Stephens, M., Pritchard, J.K. 2003. Inference of population structure using

793 multilocus genotype data: linked loci and correlated allele frequencies. Genetics 164:15677941587.

795

796 Falush, D., Stephens, M., Pritchard, J.K. 2007. Inference of population structure using 797 multilocus genotype data: dominant markers and null alleles. Mol. Ecol. Notes. 7:574-578.

798

799 Faria, R., Renaut, S., Galindo, J., Pinho, C., Melo-Ferreira, J., Melo, M., Jones, F.,

800 Salzburger, W., Schluter, D., Butlin, R. 2014. Advances in Ecological Speciation: an

801 integrative approach. Mol. Ecol. 23: 513-521.

802

803 Foll, M., Baumont, M.A., Gaggiotti, O.E. 2008. An approximate Bayesian computation

804 approach to overcome biases that arise when using AFLP markers to study population structure. Genetics 179:927-939.

806

807 Foll, M., Gaggiotti, O. 2008. A genome-scan method to identify selected loci appropriate for 808 both dominant and codominant markers: a Bayesian perspective. Genetics 180:977-995.

809

810 Fox, J. 2005. The R Commander: A basic-statistics graphical user interface to R. J. Stat. Soft.

$811 \quad 14: 1-42$. 
813 Fraley, C., Raftery, A.E. 1998. How many clusters? Which clustering methods? Answers via

814 model-based cluster analysis. Comput. J. 41:578-588.

815

816 Fraley, C., Raftery, A.E. 2002. Model-based clustering, discriminant analysis, and density

817 estimation. J. Am. Stat. Assoc. 97:611-631.

818

819 François, O., Ancelet, S., Guillot, G. 2006. Bayesian clustering using hidden Markov random 820 fields in spatial population genetics. Genetics 174:805-816.

821

822 Frantz, A.C., Cellina, S., Krier, A., Schley, L., Burke, T. 2009. Using spatial Bayesian

823 methods to determine the genetic structure of a continuously distributed population: clusters 824 or isolation by distance? J. Appl. Ecol. 46:493-505.

825

826 García-Pereira, M.J., Caballero, A., Quesada, H. 2010. Evaluating the relationship between

827 evolutionary divergence and phylogenetic accuracy in AFLP data sets. Mol. Biol. Evol. $828 \quad 27: 988-1000$.

829

830 García-Pereira, M.J., Carvajal-Rodríguez, A., Whelan, S., Caballero, A., Quesada, H. 2014.

831 Impact of deep coalescence and recombination on the estimation of phylogenetic

832 relationships among species using AFLP markers. Mol. Phylogenet. Evol. 76:102-109.

833

834 Gatesy, J. and Springer, M.S. 2013. Concatenation versus coalescence versus

835 “concatalescence”. Proc. Natl. Acad. Sci. U.S.A. 110(10). doi: 10.1073/pnas.1221121110

836

837 Gower, J.C. 1966. Some distance properties of latent root and vector methods used in 
838 multivariate analysis. Biometrika 53:325-328.

839

840 Gower, J.C. 1971. A general coefficient of similarity and some of its properties. Biometrics

$841 \quad 27: 857-874$.

842

843 Gower, J.C. 2005. Principal coordinates analysis. Encycl. Biostat. 6.

844

845 Graves, J. 2009. Deeper AFLPs. Heredity 103:99.

846

847 Grummer, J. A., Bryson, R.W., Reeder, T.W. 2013. Species delimitation using Bayes factors:

848 simulations and application to the Sceloporus scalaris species group (Squamata:

849 Phrynosomatidae). Syst. Biol.63(2):119-133.

850

851 Guillot, G., Estoup, A., Mortier, F., Cosson, J.F. 2005a. A spatial statistical model for

852 landscape genetics. Genetics 170:1261-1280.

853

854 Guillot, G., Mortier, F., Estoup, A. 2005b. Geneland: A computer package for landscape 855 genetics. Mol. Ecol. Notes. 5:708-711.

856

857 Guillot, G. 2008. Inference of structure in subdivided populations at low levels of genetic 858 differentiation. The correlated allele frequencies model revisited. Bionformatics 24:22228592228.

860

861 Guillot, G., Santos, F., Estoup, A. 2008. Analysing georeferenced population genetics data 862 with Geneland: a new algorithm to deal with null alleles and a friendly graphical user 
interface. Bioinformatics 24:1406-1407.

864

865 Guillot, G., Santos, F. 2010. Using AFLP markers and the Geneland program for the

866 inference of population genetic structure. Mol. Ecol. Res. 10:1082-1084.

867

868 Guindon, S. and Gascuel, O. 2003. A simple, fast and accurate method to estimate large

869 phylogenies by maximum-likelihood". Syst Biol. 52:696-704.

870

871 Hausdorf, B., Hennig, C. 2010. Species delimitation using dominant and codominant

872 multilocus markers. Syst. Biol. 59:491-503.

873

874 Hall, R., Holloway, J. D. (1998): Biogeography and Geological Evolution of SE Asia. -

875 Leiden (Backhuys Publishers). — 417 S. ISBN 90-73348-97-8. Zool. Reihe, 76: 158.

876 doi: 10.1002/mmnz.20000760119.

877

878 Hollingsworth, P.M., Ennos, R.A. 2004. Neighbour-joining trees, dominant markers and 879 population genetic structure. Heredity 92:490-498.

880

881 Holsinger, K.E., Lewis, P.O. 2007. HICKORY: a package for analysis of population genetic

882 data, version 1.0. Storrs : Department of Ecology and Evolutionary Biology, University of 883 Connecticut.

884

885 Jaccard, P. 1908. Nouvelle recherches sur la distribution florale. Bull. Soc. Vaudoise. Sci.

886 Nat. 44:223-270. 
888 Jakobsson, M., Rosenberg, N.A. 2007. CLUMPP: a cluster matching and permutation program for dealing with label switching and multimodality in analysis of population structure. Bioinformatics 23:1801-1806.

891

892 Jombart, T., Devillard, S., Balloux, F. 2010. Discriminant analysis of principal components: a 893 new method for the analysis of genetically structured populations. BMC Genet. 11:94. 894

Kass, R. E. and A. E. Raftery. 1995. Bayes factors. J. Amer. Stat. Assoc. 90:773-795.

896

897 Kingston, S.E., Adams, L.D., Rosel, P.E. 2009. Testing mitochondrial sequences and 898 anonymous nuclear markers for phylogeny reconstruction in a rapidly radiating group: 899 molecular systematics of the Delphininae (Cetacea: Odontoceti: Delphinidae). BMC Evol. $900 \quad$ Biol. 9:245.

901

902 Koopman, W.J.M. 2005. Phylogenetic signal in AFLP data sets. Syst. Biol. 54:197-217. 903

904 Koopman, W.J.M., Wissemann, V., De Cock, K., Van Huylenbroeck, J., De Riek, J., 905 Sabatino, G.J.H., Visser, D., Vosman, B., Ritz, C.M., Maes, B., Werlemark, G., Nybom, H., 906 Debener, T., Linde, M., Smulders, M.J.M. 2008. AFLP markers as a tool to reconstruct 907 complex relationships: a case study in Rosa (Rosaceae). Am. J. Bot. 95:353-366.

908

909 Kosman, E., Leonard, K.J. 2005. Similarity coefficients for molecular markers in studies of

910 genetic relationships between individuals for haploid, diploid, and polyploid species. Mol.

911 Ecol. 14: 415-424. 
913 Krauss, S.L. 2000. Accurate genetic diversity estimates from amplified fragment length

914 polymorphism. Mol. Ecol. 9:1241-1245.

915

916 Kronforst, M.R., Gilbert, L.E. 2008. The population genetics of mimetic diversity in

917 Heliconius butterflies. Proc. R. Soc. B. 275:493-500.

918

919 Lacépède, B.G.E.L. (Comte de). 1804. Mémoire sur plusieurs animaux de la Nouvelle

920 Hollande dont la description n'a pas encore été publiée. Ann. Mus. Hist. Nat. Paris. 4:55-58.

921

922 Latch, E.K., Dharmarajan, G., Glaubitz, J.C., Rhodes Jr, O.E. 2006. Relative performance of

923 Bayesian clustering software for inferring population substructure and individual assignment

924 at low levels of population differentiation. Conserv. Genet. 7:295-302.

925

926 Leaché, A.D., Fujita, M.K., Minin, V.N., Bouckaert, R.R. 2014. Species delimitation using 927 genome-wide SNP data. Syst. Biol. 63: 534-542.

928

929 Luo, R., Hipp, A.L., Larget, B. 2007. A bayesian model of AFLP marker evolution and 930 phylogenetic inference. Stat. Appl. Genet. Mol. Biol. 6:11.

931

932 Malhotra, A., Thorpe, R.S. 2000. A phylogeny of the Trimeresurus group of pit vipers: new 933 evidence from a mitochondrial gene tree. Mol. Phylogenet. Evol.16:199-211.

934

935 Malhotra, A., Thorpe, R.S. 2004a. Maximizing information in systematic revisions: a

936 combined molecular and morphological analysis of a cryptic green pitviper complex,

937 Trimeresurus stejnegeri. Biol. J. Linn. Soc. 82:219-235. 
938

939 Malhotra, A., Thorpe, R.S. 2004b. A phylogeny of four mitochondrial gene regions suggests

940 a revised taxonomy for Asian pitvipers (Trimeresurus and Ovophis). Mol. Phylogenet. Evol.

$941 \quad 32: 83-100$.

942

943 Malhotra, A., Thorpe, R.S., Mrinalini, Stuart, B.L. 2011a. Two new species of pitviper of the

944 genus Cryptelytrops Cope 1860 (Squamata: Viperidae: Crotalinae) from Southeast Asia.

945 Zootaxa 2757:1-23.

946

947 Malhotra, A., Dawson, K., Guo, P., Thorpe, R.S. 2011b. Phylogenetic structure and species

948 boundaries in the mountain pitviper Ovophis monticola (Serpentes: Viperidae: Crotalinae) in 949 Asia. Mol. Phylogenet. Evol. 59:444-457.

950

951 McCormack, J.E., Harvey, M.G., Faircloth, B.C., Crawford, N.G., Glenn, T.C., Brumfield, 952 R.T. 2013. A Phylogeny of birds based on over 1,500 loci collected by target enrichment and 953 high-throughput sequencing. PLoS One 8(1): e54848.

954

955

Medrano, M., Lopez-Perea, E., Herrera, C.M. 2014. Population genetics methods applied to a 956 species delimitation problem: Endemic trumpet daffodils (Narcissus Section Pseudonarcissi)

957 from the southern Iberian Peninsula. Int. J. Plant Sci. 175:501-517.

958

959 Mendelson, T.C., Simons, J.N. 2006. AFLPs resolve cytonuclear discordance and increase

960 resolution among barcheek darters (Percidae: Etheostoma: Catonotus). Mol. Phylogenet.

961 Evol. 41:445-453.

962 
963 Meudt, H.M., Clarke, A.C. 2007. Almost forgotten or latest practice? AFLP applications, 964 analyses and advances. Trends Plants Sci. 12:106-117.

965

966 Meudt, H.M., Lockhart, P.J., Bryant, D. 2009. Species delimitation and phylogeny of a New

967 Zealand plant species radiation. BMC Evol. Biol. 9:111.

968

969

Meyer, A.S., Garcia, A.A.F., de Souza, A.P., de Souza Jr, C.L. 2004. Comparison of

970

similarity coefficients used for cluster analysis with dominant markers in maize (Zea mays $L$ ).

971

Genet. Mol. Biol. 27:83-91.

972

973 Meyer, C.P., Paulay, G. 2005. DNA barcoding: error rates based on comprehensive sampling.

974 PLoS Biol. 3:e422.

975

976 Milá, B., Carranza, S., Guillaume, O., Clobert, J. 2010. Marked genetic structuring and

977 extreme dispersal limitation in the Pyrenean brook newt Calotriton asper (Amphibia:

978 Salamandridae) revealed by genome-wide AFLP but not mtDNA. Mol. Ecol. 19:108-120.

979

980 Misof, B., Liu, S., Meusemann, K., Peters, R.S., Donath, A., Mayer, C., et

981 al.: Phylogenomics resolves the timing and pattern of insect evolution. 2014. Science.

$982 \quad 346: 763-768$.

983

984 Morin, P.A., Archer. F.I., Foote, A.D., Vilstrup, J., Allen, E.E., Wade, P., Durban, J.,

985 Parsons, K., Pitman, R., Li, L., Bouffard, P., Abel Nielsen, S.C., Rasmussen, M.,

986 Willerslevm, E., Gilbert, M.T., Harkins, T. 2010. Complete mitochondrial genome

987 phylogeographic analysis of killer whales (Orcinus orca) indicates multiple species. Genome 
Res. 20:908-916.

989

990 Nie, R-E., Mochizuki, A., Brooks, S.J., Liu, Z-Q, Yang, X-K. 2012. Phylogeny of the green

991 lacewing Chrysoperia nipponensis species-complex (Neuroptera: Chrysopidae) in China,

992 based on mitochondrial and AFLP data. Ins. Sci. 19:633-642.

993

994 Ogden, R., Thorpe, R.S. 2002. The usefulness of amplified fragment length polymorphism 995 markers for taxon discrimination across graduated fine evolutionary levels in Caribbean 996 Anolis lizards. Mol. Ecol.11:437-445.

997

998 Peakall, R., Smouse, P.E. 2006. GENALEX 6: genetic analysis in Excel. Population genetic 999 software for teaching and research. Mol. Ecol. Notes 6:288-295.

1000

1001 Pelser, P.B., Gravendeel, B., Van der Meijden, R. 2003. Phylogeny reconstruction in the gap 1002 between too little and too much divergence: the closest relatives of Senecio jacobaea 1003 (Asteraceae) according to DNA sequences and AFLPs. Mol. Phylogenet. Evol. 29:613-628. 1004

Pérez-Figueroa, A., Garcia-Pereira, M.J., Saura, M., Rolan-Alvarez, E., Caballer, A. 2010.

1006 Comparing three different methods to detect selective loci using dominant markers. J. Evol. 1007 Biol. 23:2267-2276.

1008

1009 Posada, D. 2008. jModelTest: Phylogenetic model averaging. Mol. Biol. Evol. 25:125310101256.

1011

1012 Posada, D., Crandall, K.A. 1998. Modeltest: testing the model of DNA substitution. 
1013 Bioinformatics 14:817-818.

1014

1015 Prebble, J.M., Meudt, H.M., Garnock-Jones, P.J. 2012. Phylogenetic relationships and 1016 species delimitation of New Zealand bluebells (Wahlenbergia, Campanulaceae) based on 1017 analyses of AFLP data. New Zeal. J. Botany 50:365-378.

1018

1019 Pritchard, J.K., Stephens, M., Donnelly, P. 2000. Inference of population structure using 1020 multilocus genotype data. Genetics 155:945-959.

1021

1022 Pritchard, J.K., Wen, X., Falush, D. 2007. Documentation for STRUCTURE software:

1023 Version 2.2. http://pritch.bsd.uchicago.edu/software/structure22/readme.pdf.

1024

1025 Quek, S-P., Counterman, B.A., de Moura, P.A., Cardoso, M.Z., Marshall, C.R., McMillan,

1026 W.O., Kronforst, M.R. 2010. Dissecting comimetic radiations in Heliconius reveals divergent 1027 histories of convergent butterflies. Proc. Natl. Acad. Sci. U.S.A. 107:7365-7370.

1028

1029 Rambaut, A., Drummond, A.J. 2008. FigTree v1.1.2. Available from:

1030 http://tree.bio.ed.ac.uk/software/figtree.

1031

1032 Reeves, P.A., Richards, C.M. 2011. Species delimitation under the general lineage concept:

1033 An empirical example using wild north American hops (Cannabaceae: Hummulus lupulus). 1034 Syst. Biol. 60:45-59.

1035

1036 Ronquist, F., Huelsenbeck, J.P. 2003. MrBayes 3: Bayesian phylogenetic inference under 1037 mixed models. Bioinformatics 19:1572-1574. 
1039 Rosenberg, N.A. 2004. DISTRUCT: a program for the graphical display of population

1040 structure. Mol. Ecol. Notes. 4:137-138.

1041

1042 Sambrook, J., Fritsch, E.F., Maniatis, T.E. 1989. Molecular cloning: A laboratory manual. $2^{\text {nd }}$

1043 edition. Cold Spring Harbour, New York: Cold Spring Harbour Laboratory Press.

1044

1045 Sanders, K.L., Malhotra, A. and Thorpe, R.S. 2004. Ecological diversification in a group of

1046 Indomalayan pitvipers (Trimeresurus): convergence in taxonomically important traits has

1047 implications for species identification. J. Evol. Biol., 17:721-731.

1048

1049 Sanders, K.L., Malhotra, A. and Thorpe, R.S. 2006. Evidence for a Müllerian mimetic 1050 radiation in Asian pitvipers. Proc. Biol. Sci. 273:1135-1141.

1051

1052 Song, S., Liu, L., Edwards, S.V., Wu, S. 2012. Resolving conflict in eutherian mammal 1053 phylogeny using phylogenomics and the multispecies coalescent model. Proc. Natl. Acad.

1054 Sci. U.S.A. 109(37):14942-14947.

1055

1056 Springer, M.S., Meredith, R.W., Gatesy, J., Emerling, C.A., Park, J., Rabosky, D.L. Stadler,

1057 T., Steiner, C., Ryder, O.A., Janečka,J.E., Fisher, C.A., Muryphy, W. 2012.

1058 Macroevolutionary dynamics and historical biogeography of primate diversification inferred 1059 from a species supermatrix. PLoS One. 7:1-23. 
1061 Vogel, G., David, P., Pauwels, O.S.G. 2004. A review of morphological variation in

1062 Trimeresurus popeiorum (Serpentes: Viperidae: Crotalinae) with the description of two new 1063 species. Zootaxa 727:1-63.

1064

1065 Voris, H.K. 2000. Special Paper 2: Maps of Pleistocene sea levels in Southeast Asia:

1066 shorelines, river systems and time durations. J. Biogeog. 27:1153-1167.

1067

1068 Vos, P., Hogers, R., Bleeker, M., Reijans, M., van de Lee, T., Hornes, M., Frijters, A., Pot, J., 1069 Peleman, J., Kuiper, M. 1995. AFLP: a new technique for DNA fingerprinting. Nucleic Acids $1070 \quad$ Res. 23:4407-4414.

1071

1072 Weisrock, D.W., Rasoloarison, R.M., Fiorentino, I., Ralison, J.M., Goodman, S.M., 1073 Kappeler, P.M., Yoder, A.D. 2010. Delimiting species without nuclear monophyly in 1074 Madagascar's mouse lemurs. PLoS ONE 5:e9883.

1075

1076 Werle, E., Schneider, C., Renner, M., Volker, M., Fiehn, W. 1994. Convenient single-step, 1077 one tube purification of PCR products for direct sequencing. Nucleic Acids Res. 22:435410784355.

1079

1080 Whitlock, R., Hipperson, H., Mannarelli, M., Burke, T. 2008. A high-throughput protocol for 1081 extracting high-purity genomic DNA from plants and animals. Mol. Ecol. Res. 8:736-741.

1082 Whitlock, R., Hipperson, H., Mannarelli, M., Butlin, R.K., Burke, T. 2008. An objective, 1083 rapid and reproducible method for scoring AFLP peak-height data that minimizes genotyping

1084 error. Mol. Ecol. Res. 8:725-735.

1085 
1086 Wilgenbusch, J.C., Warren, D.L., Swofford, D.L. 2004. AWTY: a system for graphical

1087 exploration of MCMC convergence in Bayesian phylogenetic inference. Available from:

1088 http://ceb.csit.fsu.edu/awty.

1089

1090 Wooten, J.A., Camp, C.D., Rissler, L.J. 2010. Genetic diversity in a narrowly endemic,

1091 recently described dusky salamander, Desmognathus folkertsi, from the southern

1092 Appalachian Mountains. Conserv. Genet. 11:835-854.

1093

1094 Yeh, F.C., Yang, R.C., Boyle, T.B.J., Ye, Z.H., Mao, J.X. 1997. POPGENE, the

1095 user-friendly shareware for population genetic analysis. Molecular Biology and

1096 Biotechnology Centre, University of Alberta, Canada.

1097

1098 Zhang, D-X., Hewitt, G.M. 2003. Nuclear DNA analyses in genetic studies of populations:

1099 practice, problems and prospects. Mol. Ecol. 12:563-584.

1100 


\section{FIGURE CAPTIONS}

Figure 1. Map of southeast Asia showing sampling scheme for mtDNA and AFLP analysis of the three putative species formerly assigned to Trimeresurus macrops, plus closely related species T. venustus and T. kanburiensis. MtDNA analysis included 39 samples and AFLP genotyping included 50 samples, of which 34 were also used in mtDNA analysis. The datasets used for the samples are represented by: empty circles (mtDNA); solid circle (AFLP); solid circle inside empty circle (both mtDNA and AFLP). Each location may represent multiple overlapping samples. The distribution of species in T. macrops s.l. is based on Malhotra et al. (2011a) and represents: T. macrops sensu stricto (orange); $T$. cardamomensis (blue); and T. rubeus (red). Samples in clear represent Trimeresurus kanburiensis from west Thailand and T. venustus from southern Thailand and Malaysia.

Figure 2. Mixed-model Bayesian phylogenetic reconstructions showing multiple distinct clades in the Trimeresurus macrops complex. 50\% majority-rule consensus phylograms with Bayesian posterior probabilities derived from a) mtDNA and b) Total evidence dataset. The phylogenies are highly congruent and show three distinct clades corresponding to $T$. macrops sensu stricto, T. cardamomensis, and T. rubeus.

Figure 3. Population structure of the Trimeresurus macrops complex and T. venustus estimated using STRUCTURE. Summary plot shows estimated population assignments based on $\mathrm{K}=4$ with each color corresponding to a species.

Figure 4. Map of posterior probabilities of species membership and spatial location of genetic discontinuities estimated in GENELAND. Three clusters $(K=3)$ could be 
visualized from the posterior distributions. The three plots represent assignment of pixels to each cluster: a) T. macrops sensu stricto and T. cardamomensis; b) T. rubeus; and c) T. venustus. Lightest colours indicate highest probabilities of membership and contour lines represent the spatial position of genetic discontinuities between species.

\section{Figure 5. Scatter plots from multivariate analyses showing four clusters representing} three species in T. macrops s.l., and T. venustus. The four species clusters are represented by different symbols (circles: T. macrops sensu stricto; triangles: T. cardamomensis; vertical crosses: T. rubeus; and diagonal crosses: T. venustus).

a) PCoA. Eigenvectors 1 and 3 using Gower General Similarity Coefficients are plotted. b) DAPC. The first three PCs of the DAPC are plotted. c) prabclus. Gaussian clusters on dimensions 1 and 3 identified from Non-metric Multi-Dimensional Scaling 
Table 1 Pairwise $\Phi_{P T}$ values for populations of Trimeresurus macrops complex and outgroup T. venustus. $\Phi_{\text {PT }}$ were derived from AMOVA of 298 AFLP markers using 9999 random permutations. Significant $p$-values $(p<0.05)$ are highlighted by $*$.

\begin{tabular}{|l|c|c|c|c|}
\hline Species & T. macrops s.s. & T. cardamomensis & T. rubeus & T. venustus \\
\hline T. macrops s.s. & & & & \\
\hline T. cardamomensis & $0.328^{*}$ & & & \\
\hline T. rubeus & $0.555^{*}$ & $0.627^{*}$ & & \\
\hline T. venustus & $0.494^{*}$ & $0.579^{*}$ & $0.694^{*}$ & \\
\hline
\end{tabular}

Table 2 Bayes Factor Delimitation of species in the Trimeresurus macrops complex using AFLPs (298 loci). Alternate species delimitation models were tested using SNAPP BFD against the four species model (Model A). Lumping of species is indicated by parentheses. The four species model is significantly better than all other models by $2 \times \log _{\mathrm{e}} \mathrm{BF} \geq 408$.

\begin{tabular}{|c|c|c|c|c|c|}
\hline Model & Model Details & Species & ML & Rank & $\begin{array}{c}2 \times \log _{e} \\
\text { BF }\end{array}$ \\
\hline $\mathbf{A}$ & $\begin{array}{l}\text { T. macrops s.s., T. cardamomensis, T. rubeus, } \\
\text { \& T. venustus }\end{array}$ & 4 & -3757 & 1 & \\
\hline B & $\begin{array}{l}\text { (T. macrops s.s. }+T . \text { cardamomensis }+T . \\
\text { rubeus) \& T. venustus }\end{array}$ & 2 & -4587 & 5 & +1660 \\
\hline C & $\begin{array}{l}\text { (T. macrops s.S. }+ \text { T. cardamomensis), } T . \\
\text { rubeus, \& T. venustus }\end{array}$ & 3 & -3961 & 2 & +408 \\
\hline D & $\begin{array}{l}\text { (T. macrops s.s. + T. rubeus), T. } \\
\text { cardamomensis, \& T. venustus }\end{array}$ & 3 & -4384 & 4 & +1254 \\
\hline $\mathbf{E}$ & $\begin{array}{l}\text { T. macrops s.s., (T. cardamomensis }+T \text {. } \\
\text { rubeus), \& T. venustus }\end{array}$ & 3 & -4138 & 3 & +762 \\
\hline
\end{tabular}

$\mathrm{ML}=$ Marginal likelihood

$\mathrm{BF}=$ Bayes factor 